\title{
Analisa Metode VIKOR pada Rekomendasi Alat Musik Keyboard Electone Terbaik
}

\author{
Azi Arisandi ${ }^{1}$, Eka Satria Pribadi ${ }^{2}$ \\ ${ }^{1,2}$ Sistem Informasi, STIKOM Tunas Bangsa, Pematangsiantar \\ 1aziarisandi111@gmail.com, 2ekabaladewa10@gmail.com
}

\begin{abstract}
The purpose of this study is to recommend the best electone keyboard. The method used in this research is Visekriterijumsko Kompromisno Rangiranje (VIKOR) Algorithm where the data source used is obtained from the results of questionnaires and interviews. Decision Support System is an alternative to making appropriate and efficient decisions in the process of selecting electune keyboard instruments. The VIKOR algorithm is used to find the best alternative. The alternatives used are Yamaha PSR S970 (A1), Korg PA 50 (A2), Casio MZX (A3), Technis KN 2000 (A4). The results of the study using VIKOR are in the form of ranking, where the first ranking is Yamaha PSR S97 (A1) and the second is Technis KN 2000 (A4).
\end{abstract}

Keywords: Decision Support System, VIKOR, Electune Keyboard

\begin{abstract}
Abstrak
Tujuan dari penelitian adalah untuk merekomendasikan keyboard electone terbaik. Metode yang digunakan dalam penelitian Algoritma Visekriterijumsko Kompromisno Rangiranje (VIKOR) di mana sumber data yang digunakan diperoleh dari hasil kuesioner dan wawancara. Sistem Pendukung Keputusan adalah alternatif untuk membuat keputusan yang tepat dan efisien dalam proses pemilihan instrumen keyboard electone. Algoritma VIKOR digunakan untuk menemukan alternatif terbaik. Alternatif yang digunakan adalah Yamaha PSR S970 (A1), Korg PA 50 (A2), Casio MZX (A3), Technis KN 2000 (A4). Hasil penelitian menggunakan VIKOR dalam bentuk peringkat, di mana peringkat pertama adalah Yamaha PSR S97 (A1) dan peringkat kedua adalah Technis KN 2000 (A4).
\end{abstract}

Kata kunci: Sistem Pendukung Keputusan, VIKOR, Keyboard Electone

\section{Pendahuluan}

Banyak jenis sarana hiburan yang dapat diminati setiap orang salah satunya adalah musik, baik itu musik tradisional maupun musik modern. Kedua jenis musik ini memiliki perkembangan yang berbeda, musik moderen perkembangannya lebih cepat dibandingkan dengan musik tradisional dan juga peminatnya. Dikarenakan alat musik modern sangat mudah dijumpai ditempat umum begitu pula dengan musiknya sering kita jumpai di tempat umum seperti kafe, supermarket dan ditempat umum lainnya. Salah satu alat musik modern yaitu keyboard electone. Dengan banyaknya merk pada alat musik keyboard electone memberikan banyak pilihan kepada para pelaku pemain musik dan jasa sewa alat musik electone. Banyak pilihan memberikan pertimbangan dalam menentukan alat musik electone merk mana yang terbaik sesuai dengan kenginan dan kebutuhan.

Mempertimbangkan hal di atas maka penting sekali menggunakan sistem pendukung keputusan sebagai rekomendasi merk alat musik electone terbaik. Salah satu Metode yang digunakan dalam sistem pendukung keputusan adalah metode VIKOR. Metode VIKOR adalah metode perankingan dengan menggunakan indeks peringkat multikriteria berdasarkan ukuran tertentu dari kedekatan dengan solusi yang ideal [1]. Metode VIKOR mampu menyelesaikan kasus multi kriteria dalam pemilihan alat musik electone terbaik. 
Penelitian sebelumnya yang menggunakan metode VIKOR sebagai referensi penelitian ini digunakan oleh [2] yang berjudul "Penerapan Metode VIKOR Dalam Penentuan Penerima Dana Bantuan Rumah Tidak Layak Huni" penelitian ini bertujuan untuk menetukan calon penerima bantuan RUTILAHU yang berhak menerima bantuan tersebut. Metode VIKOR digunakan untuk mengatasi permasalahan multikeriteria kompleks yang berfokus pada ranking dan seleksi dari sebuah alternatif. Penelitian ini bertujuan sebagai rekomendasi dalam menentukan merk alat musik keyboard electone terbaik. Hasil analisa metode VIKOR, diharapkan dapat digunakan sebagai pendukung keputusan dalam pemilihan alat musik keyboard electone bagi pelaku musik dan jasa rental alat musik.

\section{Metode Penelitian}

\subsection{Sistem Pendukung Keputusan}

Sistem pendukung keputusan merupakan sistem informasi interaktif yang menyediakan informasi, pemodelan, dan pemanipulasian data [3]. Sistem pendukung keputusan merupakan resources individu secara intelek dengan kemampuan komputer guna meningkatkan kualitasi keputusan dan bisa sebagai manajemen pengambilan keputusan [4]. Sistem pendukung keputusan ditujukan untuk pengambilan keputusan yang bersifat analistis dalam situasi yang tidak terstruktur dan dengan kriteria yang kurang jelas.

\subsection{Sumber Data}

Data yang digunakan dalam penelitia ini adalah data perimer yaitu pemberian kuesioner kepada 25 responden yang nantinya akan dijadikan alternatif. Sedangkan Fitur (C1), Rom (C2), Body/Style (C3), Harga (C4) dan Tahun Keluaran (C5) dijadikan sebagai kriteria.

\subsection{Metode Visekriterijumsko Kompromisno Rangiranje (VIKOR)}

VIKOR merupakan suatu metode Multi Criteria Decision Making (MCDM) yang pertama kali dikembangkan dan diajukan oleh Opricovic \& Tzeng pada tahun 1998[5]. VIKOR adalah metode optimasi multi- kriteria yang digunakan dalam sistem yang kompleks. Metode ini berfokus pada perangkingan dan memilih dari satu set alternatif, dan menentukan solusi kompromi untuk masalah kriteria yang bertentangan, yang dapat membantu para pengambil keputusan untuk mencapai keputusan akhir yang tepat[3] [6]. Tujuan utama dari metode ini adalah untuk menghasilkan solusi kompromi dengan melakukan perangkingan terhadap hasil nilai alternatif dan kriteria yang bertolak belakang [7]. Langkah-langkah yang digunakan dalam metode VIKOR dalam menyelsaikan masalah di atas adalah sebagai berikut :

a. Membuat matriks keputusan alternatif dan krteria (F) dengan rumus sebagai berikut :

$$
\mathrm{X}=\underset{\ldots}{A_{1}} \begin{gathered}
A_{1} \\
\ldots \\
A_{m}
\end{gathered}\left[\begin{array}{cccc}
C_{x 1} & C_{X 2} & \ldots & C_{x n} \\
X_{11} & X_{12} & \ldots & X_{1 n} \\
X_{21} & X_{22} & \ldots & X_{2 n} \\
\ldots & \vdots & \ddots & \vdots \\
X_{11} & X_{11} & \ldots & X_{11}
\end{array}\right]
$$

Dimana $\mathrm{X}$ merupakan matriks keputusan, $A_{1}$ alternatif ke $-i, i=1,2,3$ adalah numor urutan alternatif dan $C_{j}$ kriteria ke- $j, j=1,2,3 . . \mathrm{m}$ adalah nomor urutan kriteria, serta $X_{\mathrm{i} j}$ adalag respon alternatif pada kriteria.

b. Menetukan bobot untuk setiap kriteria (W) dengan rumus di bawah ini :

$$
W=\Sigma_{j}^{n}=W_{j}=1
$$


Dimana $W_{j}$ adalah bobot kriteria dan $\mathrm{j}=1,2,3$ merupakan nomor urutan kriteria.

c. Membuat matriks normalisasi (N) dengan mencari nilai maximum dan minimum untuk mendapatkan solusi ideal dari setiap kriteria. Dengan rumus sebagai berikut:

$$
N_{i j}=\frac{(\max X i j-x i j)}{(\max x i j-\min x i j)}
$$

Dimana :

$$
\begin{array}{ll}
\mathrm{Nij} & =\text { nilai normalisasi sampel } \mathrm{i} \text { kriteria } \mathrm{j} \\
\mathrm{Xij} & =\text { nilai data sampel } \mathrm{i} \text { kriteria } \mathrm{j} \\
\mathrm{Max} \mathrm{Xij} & =\text { nilai maksimum suatu kriteria } \\
\mathrm{Min} \mathrm{Xij} & =\text { nilai minimum suatu kriteria } \\
\mathrm{I} & =\text { alternatif } \\
\mathrm{J} & =\text { kriteria }
\end{array}
$$

d. Menghitung matriks normalisasi bobot

Normalisasi bobot dilakukan dengan cara melakukan perkalian bobot kriteria (W) dengan nilai data yang sudah dinormalisasi (N). Dengan rumus sebagai berikut:

$$
F i j=W_{j} . N i j
$$

Dimana Fij adala hasil normalisasi bobot dari alternatif, Wj nilai bobot kriteria da Nij data ternormalisasi dari alternatif dan kriteria.

e. Menghitung Utility measure (S) dan regret measure (R) dari setap alternatif, dengan rumus sebagai berikut :

$$
\begin{aligned}
& S i=\sum_{j}^{n}=i W_{j} \frac{(\max X i j-x i j)}{(\max X i j-\min x i j)} \\
& R i=\operatorname{maxj} \frac{(\max X i j-x i j)}{(\max X i j-\min x i j)}
\end{aligned}
$$

Dimana Si adalah maximum group utility dan Ri adalah minimum individual regret yang diambil dari titik tejauh dan terdekat sebagau solusi ideal.

f. Menghitung Indeks VIKOR dengan rumus seagai berikut :

$$
Q i=v \frac{(\mathrm{Si}-\min \mathrm{Si})}{(\max \mathrm{Si}-\min S i)}+(1-v) \frac{(\mathrm{Rij}-\min \mathrm{Rij})}{(\max R i j-\min R i j)}
$$

Dimana $\mathrm{V}=0,5$.

\section{Hasil Pembahasan}

Dari hasil penyebaran angket di Pematangsiantar, dalam menentukan kriteria peneliti melakukan wawancara terhadap 15 pemain keyboard electone. Berikut adalah data kuesioner yang telah di olah :

Tabel 1. Data kuesioner

\begin{tabular}{cccccc}
\hline Alternative & \multicolumn{5}{c}{ Criteria } \\
\hline & C1 & C2 & C3 & C4 & C5 \\
\hline A1 & 0,74 & 0,7 & 0,7 & 0,6 & 0,73 \\
A2 & 0,72 & 0,56 & 0,59 & 0,53 & 0,69 \\
A3 & 0,75 & 0,75 & 0,62 & 0,62 & 0,75 \\
A4 & 0,63 & 0,58 & 0,54 & 0,75 & 0,51 \\
\hline
\end{tabular}


Metode Vikor memerlukan nilai bobot kriteria untuk dijadikan proses perhitungan, bobot kriteria sebagai berikut :

Tabel 2. Bobot Kriteria

\begin{tabular}{cc}
\hline Kriteria & Bobot \\
\hline Fitur & 0.35 \\
Rom & 0.25 \\
Body & 0.10 \\
Harga & 0.15 \\
Tahun keluaran & 0.15 \\
\hline
\end{tabular}

Tahap-tahap pengerjaannya.

1. Membuat matrik keputusan alternatif dan kriteria $(\mathrm{F})$ dengan persamaan (1).

$\mathrm{X}=\begin{array}{ccccc}0,74 & 0,7 & 0,7 & 0,6 & 0,73 \\ 0,72 & 0,56 & 0,59 & 0,53 & 0,69 \\ 0,75 & 0,75 & 0,62 & 0,62 & 0,75 \\ 0,63 & 0,58 & 0,54 & 0,75 & 0,51\end{array}$

2. Menentukan bobot untuk setiap kriteria.

\begin{tabular}{cc}
\multicolumn{2}{c}{ Tabel 3. } \\
\hline Kriteria & Bobot Kriteria \\
\hline Fitur & 0.35 \\
Rom & 0.25 \\
Body & 0.10 \\
Harga & 0.15 \\
Tahun keluaran & 0.15 \\
\hline
\end{tabular}

3. Membuat matrik normalisasi $(\mathrm{N})$ dengan menentukan nilai maximum dan minimum untuk mendapatkan solusi ideal dari setiap kriteria dengan persamaan sebagai berikut:

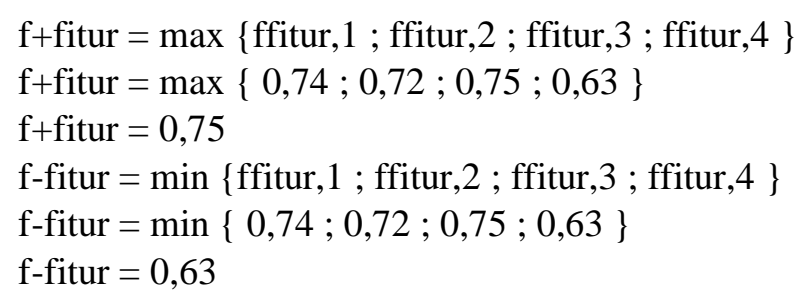

Tabel 4. Hasil Matriks Normalisasi (N)

\begin{tabular}{ccc}
\hline Kriteria & Nilai Max & Nilai Min \\
\hline Fitur & 0,75 & 0,63 \\
Rom & 0,75 & 0,56 \\
Body & 0,7 & 0,54 \\
Harga & 0,75 & 0,53 \\
Tahun keluaran & 0,75 & 0,51
\end{tabular}

4. Setelah nilai maximum dan minimum didapatkan maka selajutnya menghitung normalisasi matrik keputusan $(\mathrm{N})$ dengan persamaan (3).

$$
\begin{aligned}
& \mathrm{Na} 1, \mathrm{c} 1=\frac{0,75-0,74}{0,75-0,63}=0,08 \\
& \mathrm{Na} 1, \mathrm{c} 2=\frac{0,75-0,7}{0,75-0,56}=0,26
\end{aligned}
$$




$$
\begin{aligned}
& \mathrm{Na} 1, \mathrm{c} 3=\frac{0,7-0,7}{0,7-0,54}=0 \\
& \mathrm{Na} 1, \mathrm{c} 4=\frac{0,75-0,6}{0,75-0,53}=0,52 \\
& \mathrm{Na} 1, \mathrm{c} 5=\frac{0,75-0,73}{0,75-0,51}=0,08
\end{aligned}
$$

Setelah normalisasi bobot $\mathrm{F}^{*}$ di dapatkan, maka hasilnya dapat di lihat dibawah ini:

$$
\mathrm{X}=\begin{array}{ccccc}
1 & 1 & 0,68 & 1 & 0,25 \\
0,08 & 0,26 & 0 & 0,52 & 0,08 \\
0 & 0, & 0,31 & 0,59 & 0 \\
0 & 0,89 & 0 & 0 & 0
\end{array}
$$

5. Menghitung utility measure $(\mathrm{S})$ dan regret measure $(\mathrm{R})$ dari setiap alternatif, dengan persamaan (5) dan (6).

$$
\begin{aligned}
& \text { SA1 }=0,35+0,25+0,008+0,15+0,037=0,867 \\
& \text { RA1 }=\max \{0,35 ; 0,25 ; 0,008 ; 0,15 ; 0,037\}=0,35 \\
& \text { SA2 }=0,28+0,065+0+0,78+0,02=0,435 \\
& \text { RA2 }=\max \{0,28 ; 0,065 ; 0 ; 0,78 ; 0,02\}=0,28 \\
& \text { SA3 }=0+0+0,031+0,088+0=0,119 \\
& \text { RA3 = } \max \{0 ; 0 ; 0,031 ; 0,088 ; 0\}=0,088 \\
& \text { SA4 }=0+0,222+0+0+0=0,222 \\
& \text { RA4 }=\max \{0 ; 0,222 ; 0 ; 0 ; 0\}=0,35
\end{aligned}
$$

Dari hasil perhitungan $\mathrm{S}$ dan $\mathrm{R}$ di atas, dapat dilihat pada tabel di bawah ini :

Tabel 5. Perhitungan nilai $S$ dan $R$

\begin{tabular}{ccc}
\hline Alternatif & Nilai S & Nilai R \\
\hline A1 & 0,867 & 0,35 \\
A2 & 0,435 & 0,28 \\
A3 & 0,119 & 0,008 \\
A4 & 0,222 & 0,222 \\
\hline
\end{tabular}

Setelah hasil perhitungan $\mathrm{S}$ dan $\mathrm{R}$ didapatkan, maka langkah selanjutnya melakukan perhitungan $\mathrm{S}+, \mathrm{S}-, \mathrm{R}+, \mathrm{R}$ - dari nilai $\mathrm{S}$ dan $\mathrm{R}$. Hasil nya di bawah ini :

$$
\begin{aligned}
& \text { S+ }=\max \{0,867 ; 0,435 ; 0,119 ; 0,222\}=0,867 \\
& \text { S- }=\min \{0,867 ; 0,435 ; 0,119 ; 0,222\}=0,119 \\
& \text { R+ = max }\{0,35 ; 0,28 ; 0,008 ; 0,222\}=0,222 \\
& \text { R- = } \min \{0,35 ; 0,28 ; 0,008 ; 0,222\}=0,008
\end{aligned}
$$

6. Menghitung Indeks VIKOR dengan persamaan (7)

$$
\begin{aligned}
& \text { QA1 }=0,5[(0,867-0,119) /(0,867-0,119)]+(1-0,5)[(0,35-0,008) /(0,35- \\
& 0,008)]=1 \\
& \text { QA2 }=0,5[(0,435-0,119) /(0,867-0,119)]+(1-0,5)[(0,028-0,008) /(0,35- \\
& 0,008)]=0,24 \\
& \text { QA3 }=0,5[(0,119-0,119) /(0,867-0,119)]+(1-0,5)[(0,008-0,008) /(0,35- \\
& 0,008)]=0 \\
& \text { QA4 }=0,5[(0,222-0,119) /(0,867-0,119)]+(1-0,5)[(0,222-0,008) /(0,35- \\
& 0,008)]=0,38
\end{aligned}
$$


Hasil dari indeks vikor merupakan hasil perangkingan. Perangkingan bisa di lihat pada table di bawah ini:

Tabel 6. Hasil Perangkingan

\begin{tabular}{ccc}
\hline Alternatif & Nilai Akhir & Rangking \\
\hline A1 & 1 & 1 \\
A2 & 0,24 & 3 \\
A3 & 0 & 4 \\
A4 & 0,38 & 2 \\
\hline
\end{tabular}

\section{Kesimpulan}

Berdasarkan hasil perhitungan sistem pendukung keputusan menggunakan metode Vikor, maka peneliti menarik kesimpulan sebagai berikut:

a. Metode Vikor mendapatkan hasil perangkingan bahwa salesman Sugiono merupakan hasil perangkingan yang pertama.

b. Dalam menghitung nilai $\mathrm{S}$ dan $\mathrm{R}$ sangat berpengaruh terhadap hasil akhir yaitu perangkingan.

c. Mampu menghasilkan nilai normalisasi setiap kriteria.

\section{Daftar Pustaka}

[1] U. Terbuka, S. Informasi, and S. S. Bali, "Penerapan Metode VIKOR pada Pengambilan Keputusan Seleksi Calon Penerima Beasiswa Bidikmisi Universitas Terbuka," vol. 2, no. 1, pp. 24-35, 2018.

[2] H. Tumanggor, M. Haloho, P. Ramadhani, and S. D. Nasution, "Penerapan Metode VIKOR Dalam Penentuan Penerima Dana Bantuan Rumah Tidak Layak Huni," vol. 5, no. 1, pp. 71-78, 2018.

[3] Y. Kristyawan and A. Rizeki, "Sistem Pendukung Keputusan Distribusi Rehabilitas Sosial Rumah Tidak Layak Huni pada Kab Sampang Menggunakan Metode Vikor," vol. 2, no. 1, pp. 1-8, 2017.

[4] Y. Primadasa and H. Juliansa, "Penerapan Metode Vikor dalam Seleksi Penerimaan Bonus Pada Salesman Indihome," pp. 33-43.

[5] V. Imanuwelita, R. Regasari, M. Putri, and F. Amalia, "Penentuan Kelayakan Lokasi Usaha Franchise Menggunakan Metode AHP dan VIKOR," vol. 2, no. 1, pp. 122-132, 2018.

[6] C. Score, "Sistem Pendukung Keputusan Kelompok Penentuan Kelayakan Lokasi Pemukiman," vol. 7, no. 1, pp. 89-100, 2013.

[7] A. U. Martliong, N. Made, and S. Iswari, "Rancang Bangun Sistem Rekomendasi Restoran Menggunakan Metode AHP dan VIKOR pada Platform LINE," 2018. 